\title{
Leading Cadres' Resources and Environmental Responsibility Audit: Key Analysis and Accountability Path
}

\author{
Ya-Mei GUAN* Yuan RONG \\ Nanjing University of Finance and Economics, Nanjing City, P.R.China, 210023 \\ guanyamei@sina.com
}

\begin{abstract}
There is a great relationship between ecoenvironmental problems and the unclear environmental responsibilities of leading cadres during their tenure, the inaction of environmental governance, and insufficient accountability for environmental responsibilities. Under the background of ecological civilization, this article first discusses the connotation of leading cadre's resource and environmental responsibility audit, and analyzes the role definition of leading cadres' resource and environmental responsibility audit. On this basis, this article puts forward the focus of auditing leading cadres' resources and environmental responsibility and proposes accountability mechanisms to improve leading cadres' resources and environmental responsibility audit.
\end{abstract}

Keywords-Ecological civilization; Resources and environmental responsibility audit; Accountability path

\section{INTRODUCTION}

The audit of resources and environmental responsibility in the domestic has just begun. The relevant theories are not yet mature and the connotation and extension of resource and environmental audit are not uniform. Although the local government has implemented leading cadres' resources and environmental responsibility audit, which is based on the local conditions to set up the content of resources and environment responsibility audit. The focus of audit are vary from each other. From the perspective of leading cadres' "environmental bills", this article extracts the methods of resource and environmental responsibility audit, sum up the practical exploration of resource and environmental responsibility audit, and try to find effective ways to audit leading cadres' resources and environment responsibility so as to promote the sustainable development of domestic resources and environmental audit.

\section{THE CONNOTATION OF LEADING CADRES' RESOURCES AND ENVIRONMENTAL RESPONSIBILITY AUDIT}

The natural resources studied in this article refer to water resources, land resources, forest resources, mineral resources, marine resources, and so on. Leading cadres at all levels manage various tasks in the region and shoulder responsibilities for local resources protection and pollution control. If there are mistakes in decision making, resulting in waste of resources or environmental damage, the leader cadres will be held responsible. Xing Jianfeng (2013) pointed out that the resource and environmental audit focused on auditing the implementation of environmental protection policies and ensuring the implementation of national environmental protection policies, especially auditing the performance of environmental protection funds and projects, and improving the utilization rate of environmental protection funds and the economic efficiency of environmental protection projects. Ma Zhijuan et al. (2014) believe that during the process of auditing resources and environmental responsibility, the auditor should focus on various resources and environmental protection systems and audit the implementation of leading cadres. Therefore, the audit of leading cadres' resources and environmental responsibilities is aimed to audit the responsibilities of leading cadres in local party and government to perform resource and environment within their term of office [1]. It will focus on auditing the state of comprehensive utilization of natural resources as well as the governance of water, air, and soil pollution during their tenure. Through the audit of resources and environmental responsibilities, this article objectively evaluate the situation of leading cadres to fulfill the responsibility of resources and environment during their term of office, discover any existing problems, and investigate the responsibility of the person concerned.

\section{THE ROLE DEFINITION OF LEADING CADRES' RESOURCES AND ENVIRONMENT RESPONSIBILITY AUDIT}

\section{A. Promote local governments to adhere to green development}

Green development is an important part of the "five development concepts". Ecological civilization is a new form of civilization in the history of human civilization. It contains the connotations of material civilization, spiritual civilization, and political civilization that adapted to the times. General Secretary $\mathrm{Xi}$ Jinping has repeatedly made a statement on promoting the construction of ecological civilization vigorously, which represented the people's pursuit of a better life. Strengthening the protection of resources and environment and promoting the construction of ecological civilization reflect the inherent values of life, economic value, people's livelihood, political values, cultural values and social values and more and more people attach great importance to them. Organizing and conducting off-office auditing on leading cadres' natural 
resources assets is to make full use of auditing and supervision methods to promote local governments to adhere to green development. In the construction of ecological civilization, the concept will become a reality and green development methods will be formed, which achieve the purpose of benefiting the people. The auditing cadres at the grass-roots level should fully realize that the audit of resources and environmental responsibility is to protect the local green development.

\section{B. Promote the effective implementation of macro policies}

Leading cadres' resources and environment responsibility audit is aimed to strengthen the protection of resources and environment, promote the construction of ecological civilization, economize and use resources efficiently, and strengthen environmental governance, which is both major decisions of the central government and macroeconomic control policies. The audit of resources and environment responsibility includes a large amount of financial input at all levels and overall plan for the reform of ecological civilization system. All of those top-level design need deep implementation and solid practice at the grassroots level. Local leading cadres' responsibility for natural resource assets will be in the new normal [2]. To carry out the audit of the departure of leading cadres' natural resource assets, the role definition of grass-roots auditing agencies should be positioned to promote the effective implementation of national macroeconomic policies. Through auditing supervision, local party committees and governments are urged to strengthen the implementation of resources and environmental policies and highlight the focus of ecological and environmental protection work. In the process of seeking economic and social development, through the implementation of policies, it is important to use existing resources earnestly and efficiently, ensure that ecological environment is improved effectively and establish ecological safety barriers from a longterm perspective to create a harmonious coexistence between man and nature.

\section{Promote local leadership to make decisions scientifically}

In order to accelerate economic and social development, local party and government leaders insist on taking economic construction as the central task, making decisions and deployment around development under the dependence of local resources, placing industrial rejuvenation at the top priority, and fully promoting industrial projects by inviting investment and joint venture cooperation. At the same time, in order to improve the production and living environment, all localities are speeding up infrastructure construction. The construction of these projects is not only related to the development and utilization of resources, but also related to the protection of the ecological environment.

In addition, the traditional mode of production and development and the excessive request from resources have led to a substantial weakening of the ability of sustainable development of resources in some places. At present, local party and government leaders are responsible for developing the economy and constructing ecological civilization. Their level of decision-making directly affects the development of social economy and the protection of ecological environmental. The implementation of the off-office audit of natural resources assets is focused on promoting the scientific and normative decision-making of local party and government leaders, handling the relationship between development and protection, ensuring the sustainable development of resources, and avoiding the formation of historical debts in resources and environment.

\section{FOCUS ANALYSIS OF LEADERSHIP CADRES' RESOURCES AND ENVIRONMENTAL RESPONSIBILITY AUDIT}

\section{A. The resource and environment cover many contents}

Resources constitute the ecology, and ecology reflects the state of survival and development of organisms in a certain natural environment. And the environment related to ecology has a great impact on the survival and development of organisms. In the audit of resource and environmental responsibility, it must be fully realized that the resources and environment cover many contents. In terms of its resource composition, there are both above-ground and underground resources, both biological and non-living resources. Factors that have an impact on the resource and environment are also diverse, including natural and man-made factors. At the same time, due to the diversity of resources, the indicator systems and calculation systems that reflect the protection and utilization of resources and the influence of the ecological environment are also complicated. It is a major challenge for auditors to implement the resources and environmental responsibilities audit and face the complex and changeable situation.

\section{B. Absence of information sharing on resources and environment}

Natural resource asset management involves multiple departments, and environmental protection is the common responsibility of the entire society. Natural resources asset management and environmental protection have professional attributes. The state has proposed to gradually establish and improve the natural resources balance sheet preparation system, and to find out the natural resources assets, which are mainly led by the statistics department, are based on the data of the natural resources competent department. With the continuous economic and social development and the use of resource assets, the natural resources balance sheet has always been in a dynamic process, and has produced a large amount of professional data under the protection and utilization. At present, the utilization rate of grassroots natural resource asset management internet is not high, departments have not yet interconnected, the awareness of big data utilization is not strong, and information sharing related to natural resource assets is still in a state of absence. It will inevitably affect the effective implementation of resources and environmental responsibility audit. 


\section{A variety of factors affect the clarification of responsibilities}

In accordance with current auditing laws and administrative rules and regulations, the off-office audit of natural resources assets of leading cadres needs to determine the object of auditing based on the management authority of cadres. In a county, the management and development of natural resource assets are basically led by the local party committee and government. The direct departments, subordinate agencies, or investment promotion unit are responsible for the implementation of the management and development of natural resource assets. In the implementation, it is inevitable that there will be deviations or decisions that violate the laws of nature or the misallocation of resources. Natural laws and misallocation of resources. Under these circumstances, the emergence of these problems can be attributed to the decision-making mistakes of the higher-level party committee and government, to the management errors of the responsible department of natural resources assets, and to the execution responsibilities of the relevant departments.

\section{Limited resources and environmental auditing capabilities}

The off-office audit of leading cadres natural resources assets is a deep-level audit. It is technical and professional and involves a wide range of fields. It requires both big data calculation and application of specialized equipment. It requires auditors to understand financial auditing, compliance auditing, performance auditing and other professional knowledge. Basic knowledge such as environmental science, environmental engineering, environmental economics, environmental laws and regulations, and environmental management should be mastered too. When carrying out the audit of resources and environment responsibility, the ability to audit resources and environment is the fundamental basis. However, there is a shortage of professional talents who master the knowledge of resources and environment in grass-roots audit institutions. Existing cadres are accustomed to traditional financial audits and lack experience in resource and environmental audit, what's more, there is no ready-made model for reference [3]. The limitation of auditing ability has already been an important factor which restrict the audit of the resource and environment.

\section{IMPROVE THE ACCOUNTABILITY MECHANISM OF LEADING CADRES' RESOURCE AND ENVIRONMENTAL RESPONSIBILITY AUDIT}

So far, China has promulgated 21 environmental protection laws, 45 administrative regulations for environmental protection, 83 national regulations for environmental protection, 25 related regulations of the State Council, and 8 environmental protection standards. At the same time, China has also joined a number of international environmental treaties, the related fields include ozone layer protection, chemicals and hazardous waste, climate change, biodiversity conservation, nuclear and radiation safety and so on. However, issues such as lagging environmental management, insufficient enforcement of environmental laws, and ambiguous environmental accountability still exist. Environmental responsibility accountability subjects include government environmental protection agencies, government audit agencies, environmental policy making agencies, and other law enforcement agencies such as Procurator ate and judiciary. However, in practice, the accountability subjects lack a clear division of responsibilities, the accountability process lacks an open and transparent process, the audit results cannot be used fully and effectively, and the results of the accountability cannot be guaranteed to be fair, just and open. At present, China's environmental management relies mainly on the government's environmental protection department, and the auditing agencies play an auxiliary role in environmental management. In view of the situation above, in order to strengthen the use of environmental responsibility audit results in the accountability process, the auditing agency can transfer the environmental responsibility audit report which has been issued to the main environmental supervision department, and at the same time, through direct accountability and transfer processing, etc.,the auditing agency can investigate the relevant environmental responsibility units and environmental responsible persons according to law. The accountability results of various environmental supervision departments will be reported to the auditing agency at any time through the information platform during the treating process of the specific processing department, so that audit accountability will eventually be implemented. Discipline inspection organs investigate the violations of discipline and law found in economic responsibility auditing according to discipline and law. The environmental protection department punished those person severely who are responsible for the environmental accidents and disclosed by the audit. The organization department deposited the economic responsibility audit results report into the archives of the audited leading cadres as an important basis for the assessment, appointment and removal, reward and punishment of the audited leading cadres. When the relevant units violate the financial revenues and expenditures and financial revenue and expenditure stipulated by the state, the auditing authority will make punishment according to laws and regulations; When the auditing authority finds the matters that need to be transferred and handled during the audit, The related matters should be transferred to the relevant departments in accordance with the laws and regulations. The results of the audit may also be reported within a certain range, or may be announced to the public in an appropriate manner. They coordinate and cooperate, strengthen information exchange, form synergy, and jointly fulfill accountability for environmental responsibility, and at the same time, improve the efficiency of accountability.

In addition, it is necessary to strengthen the investigation of environmental responsibility. When someone misappropriate environmental funds, it is necessary to investigate the criminal liability of those person who are responsible for environmental illegality; when someone hide the truth in making reports for environmental management information and environmental accidents, it is necessary to take economic sanctions. At the same time, audit results announcement, audit prompts, supervision and rectification are good ways to investigate environmental responsibility. 


\section{CONCLUSION}

The organization to carry out the audit of the natural resource assets separation of the leading cadres is to make full use of the means of audit supervision, to promote the local government to adhere to the green development, to turn the idea into reality in the construction of ecological civilization, and to realize a coordinated and orderly work mechanism by the auditing organs at all levels and according to the actual needs.

\section{ACKNOWLEDGMENT}

This research was financially supported by National Social Science Fund (18AGL007).

This research was financially supported by Jiangsu Province Social Science Fund (18WTA005).

\section{REFERENCES}

[1] Roger simnett, Michael Nugent, Anna Huggins. Developing an International Assurance Standard on Carbon Emissions Disclosures [J].Accounting Horizons, 2009, 23(4):23-34.

[2] Wendy Green, Stuart Taylor. Factors that Influence Perceptions of Greenhouse Gas Assurance Provider Quality [J]. International Journal of Auditing, 2013, 17:288-307.

[3] Huggins, A., Green, W. \& Simnett, R.. The competitive market for assurance engagements on greenhouse gas information: is there a role from the accounting profession? [J]. Current Issues in Auditing, 2011, 5, (2):A1-A12 